ТОНОЯН Хорен Аветисович - доктор педагогических наук, профессор кафедры физического воспитания и допризывной подготовки Московского государственного университета технологий и управления им. К.Г. Разумовского (ПКУ) (109004, Россия, г. Москва, ул. Земляной Вал, 73; professortonoyan@mail.ru); член-корреспондент Международной академии наук педагогического образования

\title{
МЕТОДИКА ДИСТАНЦИОННОГО ПРЕПОДАВАНИЯ И КОНТРОЛЯ ДИСЦИПЛИНЫ «ФИЗИЧЕСКАЯ КУЛЬТУРА И СПОРТ» В ПЕРИОД ПАНДЕМИИ СОVID-19
}

\begin{abstract}
Аннотация. В статье представлен анализ результатов исследования по методике дистанционного обучения по дисциплине «Физическая культура и спорт» в Московском государственном университете технологии и управления им. К.Г. Разумовского (ПКУ) до и после пандемии COVID-19. На основе полученных данных разработаны практические рекомендации по повышению эффективности преподавания и контроля теоретического курса «Теория и методика физической культуры».
\end{abstract}

Ключевые слова: физическая культура и спорт, теория и методика физической культуры в период COVID-19, методика дистанционного преподавания, методы контроля, методика совершенствования преподавания в период коронавирусной инфекции

Актуальность исследования. Итогом модернизации высшего профессионального образования стало признание его многофункциональности в развитии физических, интеллектуальных, эстетических и психологических качеств. Это требует от выпускника вуза, наряду с владением профессиональной компетентностью и технологиями социальной мобильности, сформированного высокого уровня адаптивности, что, наряду с физической культурой личности, определяет необходимость формирования универсальных и специализированных компетенций [Колокатова, Чубаров, Петухова 2012; Тоноян 2005].

Учебная дисциплина «Физическая культура и спорт» в Московском государственном университете технологии и управления им. К.Г. Разумовского (ПКУ) реализуется в базовой части основной профессиональной образовательной программы по всем направлениям подготовки очной и заочной форм обучения на 1-м курсе обучения. Теоретическую часть этой дисциплины составляет теория и методика физической культуры. Дисциплина включает в себя обширный комплекс знаний, являющихся теоретическим фундаментом профессионального образования специалистов. Цель дисциплины - дать возможность будущему специалисту овладеть системой методов, средств, практических умений и навыков, обеспечивающих сохранение и укрепление здоровья, поддержание в норме и совершенствование своего физического состояния [Тоноян 2019]. Эффективность действующей методики подтверждается рубежным и итоговым контролем результатов тестирования [Темченко, Усова 2006].

В последние два года мир был поставлен перед небывалым в его истории вызовом. В конце 2019 г. в Китайской Народной Республике (КНР) возник эпицентр новой коронавирусной инфекции. 11 февраля возбудитель получил название $S A R S-C o V-2$, а болезнь, вызываемая им, - COVID-19 (Coronavirus disease 2019) [Сидоренко и др. 2020]. Ситуация оказала огромное влияние на всю систему образования, в т.ч. в Российской Федерации. И преподаватели, и студенты оказались в условиях карантина и самоизоляции. С 16 марта 2019 г. в Москве ввели ограничительные мероприятия, и все вузы, в т.ч. МГУТУ им. К.Г. Разумовского 
(ПКУ), перешли на удаленную форму обучения. Начались поиски новых методик и интерактивных технологий для эффективного проведения занятий по теоретическому разделу дисциплины «Физическая культура и спорт». Необходимо было без приостановки образовательного процесса адаптировать наработанные методики к изменившимся условиям. Сложившаяся ситуация не снимала ответственности за решение основных задач по формированию общекультурных и профессиональных компетенций у студентов с помощью теоретических знаний о физической культуре и спорте, массовом и оздоровительном, а также о спорте высших достижений, тем более что реализуемая правительством федеральная целевая программа «Электронная Россия» до 2020 г. и разработанная как ее развитие программа «Информационное общество» сформировали повышенный интерес к электронным технологиям обучения. Все студенты высших учебных заведений должны использовать информационные коммуникационные технологии (ИКТ), применять электронные, дистанционные технологии обучения и на этой базе совершенствовать свои знания и реагировать на изменяющиеся потребности быстро развивающегося общества [Инновации и традиции... 2016; Темченко, Усова 2006].

Тем не менее, понимая, что форма обучения студентов теоретическим и практическим основам физкультурных знаний в дистанционном формате меняется и требует новых информационных и интерактивных подходов для ее реализации с учетом специфики и направления подготовки вуза, мы ожидали определенных трудностей.

Цель исследования: определить эффективность методики преподавания курса лекций по «Теории и методике физической культуры» в дистанционном формате в период коронавирусной инфекции и уровень освоения теоретического материала с учетом требований, входящих в образовательную программу МГУТУ им. К.Г. Разумовского (ПКУ).

Для этого была проанализирована балльно-рейтинговая система оценок студентов по первому семестру по дисциплине «Физическая культура и спорт» до пандемии, проверены на эффективность организационно-методические основы проведения дистанционных учебных занятий по теории и методике физической культуры в период карантина.

Методика и организация исследования. В целях определения уровня информированности студентов о проблемах коронавирусной инфекции, а также влияния временной изоляции на освоение курса лекций по теории и методике физической культуры в сентябре 2020 г. было проведено анкетирование в дистанционном формате во всех учебных группах 1-го курса в Институте экономики, менеджмента и права. Проанализированы показатели балльно-рейтинговых систем оценок по теоретическому курсу «Теория и методика физической культуры» за 1-й семестр учебного года до перехода студентов на дистанционное обучение и в период карантина, когда все студенты перешли на дистанционный формат обучения, а курс лекций проводился в программе MicrosoftTeams в виде видеоконференций.

Результаты исследования и их обсуждение. Общее число студентов, принимавших участие в анкетировании, распределилось следующим образом: $30 \%-$ иногородние, $30 \%$ - жители Москвы и Московской обл. и 28\% - иностранные студенты из дальнего и ближнего зарубежья.

В результате анкетирования были получены следующие результаты. Большинство опрошенных студентов $(72,2 \%)$ считали, что вероятность заражения в университете коронавирусной инфекцией мала (от 1 до 3 баллов). На наш взгляд, это объясняется тем, что в учебных корпусах, где проходили занятия, еще до объявления о переводе на карантин были оперативно созданы 
необходимые условия для обеспечения безопасности от заражения и распространения коронавирусной инфекции.

68,5\% студентов считают, что КОВИД-19 изменил их взгляды на жизненные ценности, принципы и нормы. Они более серьезно и внимательно начали относиться к своему здоровью, вести здоровый образ жизни.

$58,3 \%$ студентов ответили, что в домашних условиях занимались утренней гигиенической гимнастикой. $81,4 \%$ студентов ответили, что не занимались активным отдыхом. На наш взгляд, это подтверждает тот факт, что большинство студентов отнеслись серьезно к требованию Роскомнадзора без весомых причин не выходить на улицу. Помешали активному отдыху и погодные и экономические условия.

Из общего числа студентов $85,1 \%$ подтвердили комфортность и удобство своих бытовых условий, позволяющих им без особых проблем проводить онлайн-занятия по лекционному курсу. Большинство студентов пользуются современными гаджетами, многие имеют стационарный компьютер, ноутбук или планшет и могут заниматься в домашних условиях.

При подготовке к занятиям и зачету $64,8 \%$ студентов воспользовались лекционным курсом, 9,2\% при подготовке использовали учебник по физической культуре, 25,9\% необходимую информацию черпали из Интернета. Большой процент пользующихся лекционным курсом объясняется тем, что весь учебный материал был размещен на информационном портале, а часть информации можно было прослушать или записать во время видеоконференции.

Наше предположение, что длительное нахождение студентов на удаленном режиме, отсутствие эффективных методик дистанционного обучения и контроля знаний по теоретическому курсу дисциплины «Теория и методика физической культуры» негативно повлияли на усвоение учебного материала, подтвердилось. В вопросе об итоговых оценках большинство студентов $(82,4 \%)$ ответили, что в период пандемии уровень знаний по дисциплине «Физическая культура и спорт» ухудшился. По всем группам средняя оценка по итоговому тестированию у студентов, которые учились в обычном режиме и зачетную сессию сдавали в аудитории, действительно оказалась выше, чем оценки, полученные в период дистанционного обучения. Средняя оценка в период пандемии снизилась у экономистов на $5 \%$, у менеджеров - на $7 \%$, у студентов государственного и муниципального управления - на $2 \%$, а у юристов - на $4 \%$.

Выводы. Если судить по масштабам распространения пандемии и отсутствию антивируса, перевод учебных занятий на удаленный режим может продолжаться не один год. Необходим поиск и разработка новых форм и методик проведения дистанционных занятий.

Действующая методика преподавания теоретического курса по разделу «Теория и методика физической культуры» в период пандемии в дистанционном формате (Teams) не позволяет более эффективно и доступно, чем в очной форме, давать учебный материал, следить за процессом усвоения учебного материала и с помощью общедидактических методов контролировать и оценивать результат освоения дисциплины.

Полученные результаты по итоговому тестированию до и после перехода студентов на дистанционную форму обучения для дисциплины «Физическая культура и спорт» показали, что дистанционный онлайн-формат менее эффективен, чем очные занятия в аудитории.

Для эффективного контроля теоретического курса в период коронавирусной инфекции необходимо разработать современные дистанционные технологии, а также новые формы контроля. В каком направлении будет продвигаться высшая школа в период коронавирусной инфекции? Как долго придется форми- 
ровать иммунитет у студентов к этому вирусу? Все эти вопросы требуют разработки плана эффективных действий с учетом замечаний и недостатков, выявленных в результате исследования [Инновации и традиции... 2016].

\section{Список литературы}

Инновации и традиции: современные вызовы развития педагогического образования (под ред. С.Е. Шишова): материалы международной научно-практической конференции. 05-06 апреля 2016 г. 2016. М.: ООО «Ваш формат». 530 с.

Колокатова Л.Ф., Чубаров М.М., Петухова Т.А. 2012. Физическая культура студентов: учебное пособие М.: Изд-во ПГУАиС. 423 с.

Сидоренко В.А., Сухоруков А.Л., Ичитовкина Е.Г., Богдасаров Ю.В. 2020. Организация психолого-психиатрической помощи сотрудникам органов внутренних дел Российской Федерации в ситуации пандемии COVID-19: методические рекомендации. М.: Изд-во ВИПК МВД России. 59 с.

Темченко B.А., Усова Т.Е. 2006. Учебные занятия по видам спорта как средство формирования мотивации к здоровому образу жизни у студентов высших учебных заведений. - Физическое воспитание студентов творческих специальностей. № 4. С. 107-114.

Тоноян Х.А. 2005. Физическая культура и здоровье: учебное пособие. Т. 1. М.: Изд-во РосЗИТЛП. 352 с.

Тоноян Х.А. 2019. Теоретико-методические аспекты подготовки квалифицированных кадров в сфере физической культуры на основе педагогических технологий: монография. М.: МУ МВД РФ им. В.Я. Кикотя. 399 с.

TONOYAN Khoren Avetisovich, Dr.Sci. (Ped.), Professor of the Chair of Physical Education and Pre-conscription Training, Moscow State University of Technology and Management named after K.G. Razumovsky (the First Cossack University) (73 Zemljanoj Val St, Moscow, Russia, 109004; professor-tonoyan@mail.ru); Corresponding Member of the International Academy of Sciences of Pedagogical Education

\section{THE METHODS OF TEACHING AND CONTROL IN THE DISCIPLINE «PHYSICAL EDUCATION AND SPORT» DURING COVID-19 PANDEMIC}

\footnotetext{
Abstract. The article presents an analysis of the results of research on the methodology of distance learning in the discipline "Physical culture and sport» at the Moscow State University of Technology and Management named after K.G. Razumovsky (PKU) before and after the COVID-19 pandemic. On the base of the obtained data, the author develops practical recommendations to improve the effectiveness of teaching and control in the theoretical course "Theory and methodology of physical culture».

Keywords: physical culture and sports, theory and methodology of physical culture during the period of COVID-19, methodology of distance teaching, control methods, methodology for improving teaching during the period of coronavirus infection
} 